\title{
Association of adverse childhood experiences (ACEs) with obesity and underweight in children
}

\author{
Tomasz Hanć ${ }^{1}$ (D) Ewa Bryl ${ }^{1} \cdot$ Paula Szcześniewska ${ }^{1} \cdot$ Agata Dutkiewicz $^{2}$. Aneta R. Borkowska ${ }^{3}$. Elżbieta Paszyńska ${ }^{4}$. \\ Agnieszka Słopień ${ }^{2} \cdot$ Monika Dmitrzak-Węglarz $^{5}$
}

Received: 1 August 2021 / Accepted: 29 September 2021 / Published online: 18 October 2021

(c) The Author(s) 2021

\begin{abstract}
Purpose The aim of the study was to test the hypothesis that adverse childhood experiences (ACEs) are related to both obesity and underweight from childhood, and that the association of ACEs with weight abnormalities is modulated by type of ACEs, sex and socioeconomic status (SES) indices.

Methods The relations between ACEs ( 0 vs $\geq 1)$, ACE accumulation and ACE type with weight status and $z$ scores BMI were assessed in 503 children aged 6-12 years from Poznan, Poland. The effects of interaction of ACEs with sex and SES on $z$ scores BMI were included in the analyses.

Results ACEs were significantly related to both obesity and underweight, in unadjusted analysis, and when sex and SES indices, such as size of place of residence, people per room in household, and parental education were controlled. The relation of ACEs with $z$ scores BMI was modulated by ACE type, parental subjective assessment of economic situation of a family and parental education. ACE accumulation was not related to an increase of obesity or underweight rate, or $z$ scores BMI.

Conclusion The study implicates the need for both obesity and underweight prevention in individuals with adverse experiences as early as in childhood.
\end{abstract}

Level of evidence III: evidence obtained from well-designed cohort study.

Keywords Adverse childhood experiences · Underweight · Overweight · Obesity · Parental education · Socioeconomic status $\cdot$ Children

Agnieszka Słopień and Monika Dmitrzak-Węglarz are the equivalent last authors.

Tomasz Hanć

tomekh@amu.edu.pl

1 Institute of Human Biology and Evolution, Faculty of Biology, Adam Mickiewicz University, ul. Uniwersytetu Poznańskiego 6, 61-614 Poznań, Poland

2 Department of Child and Adolescent Psychiatry, Poznan University of Medical Sciences, Ul. Szpitalna 27/33, 60-572 Poznań, Poland

3 Faculty of Education and Psychology, Maria Curie-Sklodowska University, Ul. Prezydenta Gabriela Narutowicza 12, 20-400 Lublin, Poland

4 Department of Integrated Dentistry, Poznan University of Medical Sciences, Ul. Bukowska 70, 60-812 Poznań, Poland

5 Psychiatric Genetics Unit, Department of Psychiatry, Poznan University of Medical Sciences, Ul. Rokietnicka 8, 60-806 Poznań, Poland

\section{Background}

Over the last decade research has revealed an association of obesity with psychosocial determinants, e.g.: adverse childhood experiences (ACEs). Examples of ACEs are childhood maltreatment, being a victim or witness of violence, parental divorce, death or disease of a family member, family problems [1]. Numerous studies have found that the risk of obesity in adults is significantly related to adversity in earlier phases of an individual's development [2-5]. A number of potential biosocial mechanisms for the association of ACEs with obesity have been proposed. The results of previous research suggest an important role of stress-induced changes of regulation in the hypothalamic-pituitary-adrenal axis, autonomic nervous system and prefrontal cortex, expressed in behavioural effects [6]. Nevertheless, the mechanisms underlying the ACEs-obesity link require further research.

Although a relationship between ACEs and body size has been found in many studies, there are two aspects of this 
link that require further investigation. First, as shown in the meta-analysis of Danese and Tan [7], the association between childhood maltreatment and obesity was best documented in adults, while studies of children and adolescents gave contrasting findings. The review of studies on the relationship between accumulation of ACEs and overweight indices in children gave significant results, nevertheless, no association was found for the most recent ACEs in children's lives and their excessive weight [1]. Recently published systematic review suggests that some incubation period may occur before the ACEs related tendency for obesity emerges and the outcomes may vary dependent on the type of ACEs and other factors, such as sex $[8,9]$. Therefore, the results on the link between ACEs and childhood obesity are inconsistent. Second, studies including possible ACE-underweight association are sparse and have produced contrasting results. The most recent research on a large sample of adolescents from the USA revealed a number of ACEs related to increasing risk of obesity but not underweight [6]. Other studies suggest that results may be diversified by sex, socioeconomic status and type of ACE. Girls may be more sensitive to the obesity-related effects of ACEs than boys [8]. One study on adults found ACEs related to obesity in women and to underweight in men [10]. Soares et al. [11] examined two birth cohorts within contrasting socioeconomic contexts: the United Kingdom and Brazil. The research showed that ACEs were related to adiposity indices in the UK adolescents, but in the Brazilian cohort ACEs were rather associated with lower waist circumference and BMI. In Danish military veterans sexual abuse in childhood was related to obesity, and emotional abuse to underweight [12]. In another study, the association of sexual abuse with obesity was confirmed in a large group of Finnish adolescents, whereas, parental unemployment was related to both obesity and underweight [13]. Finally, research on Polish children and adolescents found parental addiction to alcohol associated with underweight but not obesity [14]. These ambiguous results justify further research on the link between ACEs and both obesity and underweight, with the inclusion of the role of possible modulating factors.

The aim of the study was to assess the relationship between ACEs, BMI, and weight status in Polish children. We hypothesised that ACEs are related to both obesity and underweight from childhood, and the association of ACEs with weight abnormalities is modulated by ACE type, sex and socioeconomic status indices.

\section{Materials and methods}

\section{Ethical statements and basic information about procedure}

The study was funded by the National Science Centre, Poland, grant number: 2016/21/B/NZ5/00492. The work described has been carried out in accordance with The Code of Ethics of the World Medical Association (Declaration of Helsinki) for experiments involving humans and approved by the Institutional Bioethics Board of Poznan University of Medical Sciences (approval no. 542/14). The subjects and their legal guardians were fully informed about the research procedures and legal guardians gave a written consent to participate in the study. The only inclusion criteria were the age between 6 and 12 years and being a student of elementary school located in Poznań. There were no exclusion criteria. Poznań is one of the largest cities in Poland and the administrative capital of the province called Greater Poland Voivodeship located in west-central region of the country. The children were recruited in 11 randomly selected elementary schools. During meetings with parents at school, we presented the purpose and plan of the study. Parents interested in the research received detailed information about the study, an informed consent card and questionnaires. Data on adverse childhood experiences, height and weight measurements as well as socioeconomic (SES) factors were collected for each child.

\section{Adverse childhood experiences (ACEs) assessment}

ACEs were assessed by questions designed based on the Traumatic Events Screening Inventory-Parent Report Revised (TESI-PRR) [15]. The original TESI-PRR interview consists of 24 items covering a variety of potential traumatic events including current and previous injuries, hospitalizations, domestic violence, community violence, disasters, accidents, physical abuse, and sexual abuse. We decided to use simplified list of questions and focus rather on 7 broader ACE types addressed in the TESI-PRR. The reasoning for this procedure was to limit the risk related with the study for potentially vulnerable families and make the questions more readable in a paper-pencil form for a broad class of parents. Parents of children from the sample were asked to mark all types of events experienced by their child: (1) The life or health of the child was threatened, (2) The child experienced an event in which the life or health of another person was endangered or someone died, (3) The child was physically (e.g. hitting, pushing, choking, shaking, biting, burning, forced into any type of sexual activity) or psychologically (e.g. calling him/her in an unpleasant way, mocking, gossiping, shouting at him/her very hard, threatening him, the 
child felt rejected by someone close to him) assaulted, (4) The child was a witness of physical or psychological assault, (5) The child experienced the death of someone close to him/her, (6) The child experienced serious family problems (e.g. quarrels, conflicts, fighting, parting, alcohol problems or other addiction types, emotional or mental problems of family members), (7) The child was separated from his/her parents for many days. These experiences are hereinafter referred to in the article as 'life/health threat', 'life/health threat witness', 'violence victim', 'violence witness', 'death of someone close', 'stressful family problems' and 'long separation from parents'. As the list might not contain all possible adverse experiences of the studied children, the additional class of ACEs was included in the questionnaire: (8) other, not mentioned above, hereinafter referred to in the article as 'other unspecified' ACEs. The accumulation of adverse experiences was assessed as a sum of ACE types (ACE score) in a child's life. ACE scores were coded as 0 , $1,2,3$ and $4+$ groupings consistent with previous research $[4,16]$.

\section{Anthropometric assessment and body weight classification}

Measurement of body height was carried out with the anthropometer Seca 213, with a measurement accuracy of $\pm 1 \mathrm{~mm}$. Body weight was measured with a medical scale (TANITA MC-780) and a measurement accuracy of $\pm 100 \mathrm{~g}$. Measurements were performed by trained medical personnel. Children were measured in light clothes, between 8 am and $2 \mathrm{pm}$. Body Mass Index (BMI) was calculated on the basis of height and weight measurements. Effects of sex and age on BMI were controlled by transformation BMI into $z$ scores on the basis of World Health Organisation (WHO) growth charts [17] with the use of WHO AnthroPlus software. Underweight, overweight and obesity were diagnosed by an adequate classification of BMI under the guidance of the International Obesity Task-Force [18, 19].

\section{Characteristics of SES}

Questions concerning SES characteristics were included in the questionnaire for parents. The size of place of residence was assessed using the number of residents and divided into three categories for the purpose of statistical analysis: village, small and medium size cities (10-100 thous. residents), large city ( $>100$ thous. residents). The level of parents' education was assessed based on their level of formal education and grouped as follows: primary and vocational, secondary, higher (bachelor or master of science degree). Because such factors as significant burden on income taxes and value added tax and social security contributions the rate of people working in the grey zone in Poland was high in the time the research was conducted $[20,21]$. The direct question on income level could therefore result in increased rate of dropouts from the study and heightened the risk of collecting false data. Based on this assumption we used other measures of material status. The economic situation of a family was assessed subjectively by parents and grouped into three categories: bad, average, good, and objectively, by the people per room indicator, grouped as follows: $\geq 2,1-2, \leq 1$. The people per room indicator is widely used measure of household density that was found to be related significantly to income and socioeconomic status in previous research [22].

\section{Statistical methods}

The analyses were performed for the individuals with complete information on ACEs and weight status. Although in several cases parents did not respond to questions concerning socioeconomic characteristics of the family, they were not excluded from the sample.

The size and significance of the effects of ACEs (at least 1 type of ACEs vs 0 , or ACE scores vs 0 , or ACE types vs 0 ) and other independent variables: sex (with boys as the reference), size of place of residence (city $>100$ thous. residents as the reference), level of parents' education (higher education as the reference), parental subjective assessment of economic situation of a family ("good" as the reference) and people per room ( $\leq 1$ as the reference) on underweight (1-underweight vs. 0 -normal weight), overweight (1-overweight vs. 0 -normal weight) and obesity rates (1-obesity vs. 0-normal weight) were assessed in both unadjusted and adjusted logistic regression analysis. In adjusted analyses, the effects of ACEs-related variables were controlled for all other independent variables. Adjusted odds ratio for sex and socioeconomic indices were pooled out from the analysis including "at least 1 type of ACE vs. 0" variable and all other independent variables.

We used two-way ANOVA to assess the effects of interaction between sex, SES indicators and ACEs on $z$ scores BMI. The analysis was applied for ACEs as a nominal variable (at least 1 type of ACE vs 0 ) and for the types of ACE for which unadjusted or adjusted logistic regression analysis showed association with both underweight and overweight or obesity. ANOVA and Pearson's correlation analysis were applied to assess the relationship of ACE score with $z$ scores BMI. The size of effects was assessed with Cohen's $d$.

All tests were performed with Statistica (Version 12) software and considered to be statistically significant at $p<0.05$. 


\section{Results}

\section{Characteristics of the sample}

The sample comprised 503 children at age of 6-12 years (mean $=8.98, \mathrm{SD}=1.30$ ) with a comparable proportion of boys and girls ( 52.49 and $47.51 \%$, respectively) and with complete information on ACEs and weight status. Small rate of missing data occurred in case of other variables, such as size of place of residence $(n=16,3.18 \%)$, parents' level of education (mothers' education: $n=7,1.39 \%$ or fathers' education: $n=23$, $4.57 \%$ ), parental subjective assessment of economic situation of a family $(n=17,3.38 \%)$ or people per room $(n=6,1.19 \%)$.

The majority of the sample consisted of residents of large city $(79.47 \%)$, individuals whose parents declared 'good' family economic situation, higher education of mother $(65.32 \%)$ and father (48.17\%) living in a household of $\leq 1$ people per room (41.45\%). Almost half of the sample had experienced at least 1 type of ACE (47.51\%), the death of close person being the most frequent (18.33\%). Ten percent of the sample was classified as underweight (10.14\%), $15.91 \%$ as overweight and $4.57 \%$ as obese. The basic characteristics of the sample are presented in Table1.

\section{The effects of ACEs, sex and SES on weight status}

Unadjusted logistic regression analysis revealed associations of ACEs ( $\geq 1$ vs 0$)$ with both underweight ( $\mathrm{OR}=2.93$, 95\% CI 1.56-5.52) and obesity (OR $=5.44,95 \% \mathrm{CI}$ 1.99-14.87). Similar results were found for ACE types: violence victim, stressful family problems and long separation from parents. Other unspecified ACEs were related to underweight and overweight, and the death of someone close only with underweight. The analyses adjusted for other variables confirmed the association of ACEs ( $\geq 1$ vs 0 ), and specifically of ACE types, such as violence victim and stressful family problems, with underweight and obesity. Long separation from parents remained significantly related to underweight, and other unspecified ACEs to overweight. The association of the death of someone close with underweight lost statistical significance in adjusted analysis. When effects of ACE accumulation were tested, both underweight and obesity were significantly related only with one type of adverse experiences or accumulation of two ACE types in adjusted but not in unadjusted analysis. Further accumulation of 3 or $\geq 4$ ACE types were not associated with weight abnormalities. The results did not indicate that the accumulation/dose of ACEs is related to higher risk of underweight or obesity comparing to a single adverse experience (Table 2).

Low education of mother and father as well as $>1$ people per room were associated with excess weight in unadjusted analyses. The relation remained significant for education of mother ( $\mathrm{OR}=4.02,95 \% \mathrm{CI} 1.87-8.66$ for obesity) and father (OR $=1.60,95 \% \mathrm{CI} 1.09-2.36$ for overweight) but not for people per room in adjusted analyses. Abnormal weight was not related to child's sex, place of residence or parental subjective assessment of SES.

\section{The effects of ACEs, sex and SES interactions on $z$ scores BMI}

The analysis revealed effects of interaction between parental subjective assessment of the economic situation of the family, education of parents and ACE types on $z$ scores BMI (Table 3). Experience of violence was related to decreased $z$ scores BMI ( -0.22 vs 0.63 , Cohen's $d=0.65$ ) in children whose fathers' education was 'primary/ vocational' (Fig. 1). Separation from parents was related to an increase of $z$ scores BMI in children whose parents assessed the economic situation of the family as 'bad' ( 2.15 vs 0.18 , Cohen's $d=1.39$ ) and whose mothers' education was primary or vocational ( 2.53 vs. 0.66 , Cohen's $d=1.95$ ) in comparison to children with no ACEs (Figs. 2 and 3). There were no significant interaction effects of ACEs and sex, places of residence and people per room on $z$ scores BMI.

A negative trend was observed in the relationship between the number of ACEs and $z$ scores BMI, nevertheless the correlation was not significant $(r=-0.02, p=0.71)$ and the ANOVA showed that the differences in $z$ scores between the categories of ACE accumulation were not significant (Fig. 4).

\section{Discussion}

The research revealed a high prevalence of adverse childhood experiences among the examined children and youths. Almost half of the sample had experienced at least one type of ACE. This result is consistent with other cross-sectional studies that showed a high life time frequency of traumatic stimuli in youth [6]. Taking into consideration the wide scale of the problem, there is a need for a reliable assessment of the consequences of ACEs for physical and mental health, especially in childhood and adolescence, which are periods of increased sensitivity to stress [23].

The results of the study justify the statement that the one of the earliest comorbid conditions of ACEs is an abnormal weight. It has been suggested previously that the link between ACEs and obesity may not be expressed in children because of their dependency on caregivers, also in the aspect of food consumption [24]. Contrary to this, our study confirmed a significant association between ACEs and obesity in Polish children and adolescents. This finding of the ACEobesity link examination is consistent with relevant studies 
Table 1 Basic statistics by weight status

\begin{tabular}{|c|c|c|c|c|c|}
\hline & Full sample & $z \mathrm{BMI}$, mean (SD) & Underweight & Overweight & Obesity \\
\hline Age, mean (SD) & $8.98(1.30)$ & & $8.95(1.30)$ & $9.11(1.27)$ & $8.98(1.31)$ \\
\hline \multicolumn{6}{|l|}{ Sex, $n(\%)$} \\
\hline Boys & $264(52.49)$ & $0.40(1.28)$ & $22(8.33)$ & $45(17.05)$ & $12(4.55)$ \\
\hline Girls & $239(47.51)$ & $0.25(1.13)$ & $29(12.13)$ & $35(14.64)$ & $13(5.44)$ \\
\hline \multicolumn{6}{|l|}{ Place of residence $n(\%)$} \\
\hline Villages & $40(8.21)$ & $0.03(1.18)$ & $8(20.00)$ & $4(10.00)$ & $1(2.50)$ \\
\hline Small and medium size city (10-100 thous. residents) & $60(12.32)$ & $0.43(1.40)$ & $4(6.67)$ & $9(15.00)$ & $5(8.33)$ \\
\hline Large city (> 100 thous. residents) & $387(79.47)$ & $0.33(1.18)$ & $38(9.82)$ & $61(15.76)$ & $18(4.65)$ \\
\hline \multicolumn{6}{|l|}{$\begin{array}{l}\text { Parental subjective assessment of economic situation of a } \\
\text { family, } n(\%)\end{array}$} \\
\hline $\mathrm{Bad}$ & $17(3.50)$ & $0.70(1.50)$ & $1(5.88)$ & $3(17.65)$ & $2(11.76)$ \\
\hline Average & $312(64.20)$ & $0.34(1.23)$ & $32(10.26)$ & $53(16.99)$ & $16(5.13)$ \\
\hline Good & $157(32.30)$ & $0.23(1.17)$ & $18(11.46)$ & $19(12.10)$ & $7(4.46)$ \\
\hline \multicolumn{6}{|l|}{ People per room, $n(\%)$} \\
\hline$\geq 2$ & $100(20.12)$ & $0.43(1.35)$ & $11(11.00)$ & $17(17.00)$ & $8(8.00)$ \\
\hline$>1$ and $<2$ & $191(38.43)$ & $0.30(1.25)$ & $20(10.47)$ & $34(17.80)$ & $11(5.67)$ \\
\hline$\leq 1$ & $206(41.45)$ & $0.28(1.11)$ & $20(9.71)$ & $26(12.62)$ & $6(2.91)$ \\
\hline \multicolumn{6}{|l|}{ Education of mother, $n(\%)$} \\
\hline Primary & $4(0.81)$ & $0.85(1.48)$ & 0 & $1(25.00)$ & $1(25.00)$ \\
\hline Vocational & $48(9.68)$ & $0.97(1.49)$ & $2(4.17)$ & $11(22.92)$ & $9(18.75)$ \\
\hline Secondary & $120(24.19)$ & $0.45(1.41)$ & $14(11.67)$ & $22(18.22)$ & $10(8.33)$ \\
\hline Higher & $324(65.32)$ & $0.20(1.05)$ & $33(10.19)$ & $46(14.20)$ & $5(1.54)$ \\
\hline \multicolumn{6}{|l|}{ Education of father, $n(\%)$} \\
\hline Primary & $15(3.13)$ & $0.70(1.46)$ & $1(6.67)$ & $2(13.33)$ & $2(13.33)$ \\
\hline Vocational & $92(19.17)$ & $0.77(1.29)$ & $5(5.43)$ & $28(30.43)$ & $8(8.70)$ \\
\hline Secondary & $137(28.54)$ & $0.44(1.24)$ & $11(8.03)$ & $21(15.33)$ & $9(6.57)$ \\
\hline Higher & $236(48.17)$ & $0.11(1.05)$ & $29(12.29)$ & $27(11.44)$ & $4(1.69)$ \\
\hline \multicolumn{6}{|l|}{ ACE, $n(\%)$} \\
\hline 0 & $264(52.49)$ & $0.30(1.06)$ & $17(6.44)$ & $42(15.91)$ & $5(1.89)$ \\
\hline At least 1 type & $239(47.51)$ & $0.36(1.37)$ & $34(14.23)$ & $38(15.90)$ & $20(8.37)$ \\
\hline \multicolumn{6}{|l|}{ ACE score, $n(\%)$} \\
\hline 1 & $120(23.86)$ & $0.45(1.31)$ & $16(13.33)$ & $19(15.83)$ & $11(9.17)$ \\
\hline 2 & $64(12.72)$ & $0.36(1.57)$ & $12(18.75)$ & $9(14.06)$ & $8(12.50)$ \\
\hline 3 & $25(4.97)$ & $0.22(1.15)$ & $3(12.00)$ & $5(20.00)$ & 0 \\
\hline 4 & $19(3.78)$ & $0.31(1.26)$ & $2(10.53)$ & $4(21.05)$ & 0 \\
\hline 5 & $6(0.80)$ & $0.42(1.46)$ & 0 & $1(15.67)$ & $1(16.67)$ \\
\hline 6 & $4(0.80)$ & $-0.88(1.43)$ & $1(25.00)$ & 0 & 0 \\
\hline 7 & $1(0.20)$ & -0.48 & 0 & 0 & 0 \\
\hline 8 & 0 & & - & - & - \\
\hline \multicolumn{6}{|l|}{ Type of ACE } \\
\hline Life/health threat & $43(8.55)$ & $0.11(1.21)$ & $6(13.95)$ & $5(11.62)$ & $2(4.65)$ \\
\hline Life/health threat witness & $38(7.55)$ & $0.51(0.97)$ & $1(2.63)$ & $4(10.53)$ & $2(5.26)$ \\
\hline Violence victim & $45(8.95)$ & $0.11(1.51)$ & $8(17.78)$ & $5(11.11)$ & $4(8.89)$ \\
\hline Violence witness & $35(6.99)$ & $0.30(1.38)$ & $3(8.57)$ & $7(20.00)$ & $2(5.71)$ \\
\hline Death of someone close & $92(18.33)$ & $0.26(1.30)$ & $12(13.04)$ & $13(14.13)$ & $5(5.43)$ \\
\hline Stressful family problems & $90(17.93)$ & $0.33(1.43)$ & $14(15.56)$ & $14(15.56)$ & $9(10.00)$ \\
\hline Long separation from parents & $69(13.77)$ & $0.27(1.43)$ & $11(15.94)$ & $11(15.94)$ & $6(8.70)$ \\
\hline Other unspecified & $24(4.87)$ & $0.34(1.52)$ & $4(16.67)$ & $7(29.17)$ & $1(4.17)$ \\
\hline$N$ (\% of full sample) & 503 & & $51(10.14)$ & $80(15.91)$ & $25(4.97)$ \\
\hline
\end{tabular}

$A C E s$ adverse childhood experiences, $z B M I z$ scores for BMI, $n$ number, $\%$ percent, $S D$ standard deviation 
Table 2 The logistic regression analysis' results for weight status as dependent variables and ACEs, sex and socioeconomic status as predictors

\begin{tabular}{|c|c|c|c|c|c|c|}
\hline & \multicolumn{3}{|c|}{ Unadjusted analyses* } & \multicolumn{3}{|c|}{ Analyses adjusted for all other variables* } \\
\hline & Underweight & Overweight & Obesity & Underweight & Overweight & Obesity \\
\hline & OR $(95 \% \mathrm{CI})$ & OR $(95 \% \mathrm{CI})$ & OR $(95 \% \mathrm{CI})$ & OR $(95 \% \mathrm{CI})$ & OR $(95 \% \mathrm{CI})$ & OR $(95 \% \mathrm{CI})$ \\
\hline Sex (Reference: boys) & $1.58(0.86-2.88$ & $0.89(0.54-1.45)$ & $1.24(0.55-2.79)$ & $1.54(0.78-3.02)$ & $1.01(0.60-1.69)$ & $1.76(0.67-4.62)$ \\
\hline $\begin{array}{l}\text { Place of residence (Refer- } \\
\text { ence: city }>100 \text { thous. } \\
\text { residents as the refer- } \\
\text { ence) }\end{array}$ & $1.32(0.86-2.04)$ & $0.85(0.54-1.34)$ & $1.02(0.51-2.03)$ & $1.26(0.77-2.06)$ & $0.83(0.51-1.35)$ & $1.09(0.45-2.61)$ \\
\hline $\begin{array}{l}\text { Parental subjective } \\
\text { assessment of economic } \\
\text { situation of a family } \\
\text { (Reference: 'good') }\end{array}$ & $0.88(0.50-1.54)$ & $1.40(0.86-2.29)$ & $1.46(0.67-3.19$ & $0.66(0.34-1.30)$ & $1.33(0.77-2.32)$ & $0.57(0.22-1.50)$ \\
\hline $\begin{array}{l}\text { People per room } \\
\text { (Reference: } \leq 1 \text { person/ } \\
\text { room) }\end{array}$ & $1.14(0.77-1.69)$ & $1.29(0.93-1.78)$ & $1.78(1.05-3.01)$ & $1.05(0.64-1.70)$ & $0.95(0.65-1.38)$ & $1.29(0.67-2.48)$ \\
\hline $\begin{array}{l}\text { Education of mother (Ref- } \\
\text { erence: 'higher educa- } \\
\text { tion') }\end{array}$ & $0.94(0.57-1.54)$ & $1.51(1.07-2.12)$ & $4.02(2.36-6.85)$ & $1.12(0.53-2.38)$ & $1.01(0.63-1.60)$ & $4.02(1.87-8.66)$ \\
\hline $\begin{array}{l}\text { Education of father (Refer- } \\
\text { ence: 'higher education') }\end{array}$ & $0.74(0.47-1.15)$ & $1.78(1.31-2.41)$ & $2.54(1.48-4.36)$ & $0.75(0.42-1.33)$ & $1.60(1.09-2.36)$ & $1.10(0.53-2.28)$ \\
\hline $\begin{array}{l}\text { At least } 1 \text { type of ACE } \\
\text { (Reference: } 0 \text { ) }\end{array}$ & $2.93(1.56-5.52)$ & $1.23(0.75-2.01)$ & 5.44 (1.99-14.87) & $3.48(1.70-7.10)$ & $1.14(0.66-1.99)$ & $5.46(1.80-16.56)$ \\
\hline \multicolumn{7}{|l|}{ ACE score (Reference: 0) } \\
\hline 1 & $1.62(0.82-3.24)$ & $1.03(0.56-1.88)$ & $3.12(0.84-11.57)$ & $3.27(1.44-7.41)$ & $1.24(0.63-2.43)$ & $6.61(2.05-21.37)$ \\
\hline 2 & $1.14(0.77-1.70)$ & $1.00(0.71-1.39)$ & $1.81(0.83-3.94)$ & $2.24(1.39-3.63)$ & $0.97(0.60-1.57)$ & $2.60(1.21-5.57)$ \\
\hline 3 & $1.08(0.73-1.59)$ & $1.02(0.71-1.47)$ & - & $1.38(0.84-2.26)$ & $1.10(0.74-1.62)$ & - \\
\hline $4+$ & $0.94(0.54-1.63)$ & $1.05(0.62-1.79)$ & $1.33(0.62-2.83)$ & $1.00(0.61-1.63)$ & $1.05(0.79-1.39)$ & $1.06(0.58-1.92)$ \\
\hline \multicolumn{7}{|l|}{$\begin{array}{l}\text { Type of ACE } \\
\text { (Reference: } 0 \text { - no ACE } \\
\text { reported) }\end{array}$} \\
\hline Life/health threat & $2.67(0.96-7.45)$ & $0.79(0.29-2.17)$ & $2.67(0.49-14.47)$ & $2.62(0.81-8.55)$ & $0.91(0.31-2.62)$ & $1.51(0.15-15.60)$ \\
\hline Life/health threat witness & $0.40(0.05-3.19)$ & $0.61(0.20-1.84)$ & $2.58(0.48-13.99)$ & $1.40(0.15-13.55)$ & $0.52(0.16-1.70)$ & $1.00(0.09-10.52)$ \\
\hline Violence victim & 3.57 (1.39-9.15) & $0.85(0.31-2.34)$ & $5.71(1.44-22.68)$ & $4.92(1.63-14.82)$ & $0.98(0.34-2.87)$ & $6.31(1.20-33.21)$ \\
\hline Violence witness & $1.63(0.44-6.06)$ & $1.45(0.58-3.61)$ & $3.48(0.63-19.10)$ & $0.71(0.07-6.76)$ & $1.63(0.59-4.50)$ & $3.92(0.59-26.23)$ \\
\hline Death of someone close & $2.46(1.10-5.50)$ & $1.00(0.50-1.98)$ & $3.23(0.90-11.56)$ & $2.52(0.98-6.47)$ & $0.99(0.46-2.16)$ & $3.07(0.69-13.57)$ \\
\hline Stressful family problems & $6.79(2.17-21.21)$ & $1.26(0.64-2.48)$ & $6.79(2.17-21.21)$ & $5.10(1.86-14.00)$ & $1.15(0.52-2.58)$ & $6.00(1.46-24.65)$ \\
\hline $\begin{array}{l}\text { Long separation from } \\
\text { parents }\end{array}$ & $3.35(1.45-7.78)$ & $1.28(0.60-2.70)$ & $5.85(1.70-20.19)$ & $3.91(1.48-10.32)$ & $1.06(0.44-2.53)$ & $2.96(0.63-13.83)$ \\
\hline Other unspecified & $4.17(1.20-14.50)$ & $2.78(1.03-7.51)$ & $3.33(0.36-31.15)$ & $4.93(0.96-25.40)$ & 3.62 (1.11-11.79) & $2.08(0.15-28.89)$ \\
\hline
\end{tabular}

*Incidence of underweight, overweight, obesity were tested against the reference - normal weight

ACEs adverse childhood experiences, $O R$ odds ratio, $C I$ confidence interval, bold the relation is statistically significant at the level of $<0.05$

on adults [2-5] and several studies on children and adolescents $[6,13,25,26]$. However, unlike most of the previous research [1], our research does not support a stepwise positive association between accumulation of ACEs and obesity rates. The relation was became weaker from 1 to 2 ACEs, and for $>2$ ACEs it lost statistical significance. However, the summary score of the number of ACEs does not take into consideration that different ACEs may cause different psychological and physiological responses [27] and, as we have shown in the study, have varied effects on weight. The outcome of accumulation of different types of ACEs may be a compromise between an action of both mechanisms, leading to increase and decrease of the weight of a child. What is more, the study revealed that different types of ACE interact specifically with other variables. Therefore, the type of ACEs and its duration may be more predictive for weight change direction than the summary ACE score. In addition, recent studies indicate that the influence of ACEs on the development of childhood obesity may take up to $2-5$ years [8]. In our study, we do not have access to information when 
Table 3 The main effects of ACEs and interactions between ACEs and socioeconomic factors from the two-way ANOVA

\begin{tabular}{|c|c|c|c|c|c|c|c|c|c|c|c|c|c|c|}
\hline & \multirow{2}{*}{\multicolumn{2}{|c|}{$\begin{array}{l}\text { Main effects } \\
\text { of ACEs }\end{array}$}} & \multicolumn{12}{|c|}{ Interaction effects } \\
\hline & & & \multicolumn{2}{|l|}{$\overline{\operatorname{Sex}}$} & \multicolumn{2}{|c|}{$\begin{array}{l}\text { Place of } \\
\text { residence }\end{array}$} & \multicolumn{2}{|c|}{$\begin{array}{l}\text { Parental } \\
\text { subjective } \\
\text { assessment } \\
\text { of economic } \\
\text { situation of a } \\
\text { family }\end{array}$} & \multicolumn{2}{|c|}{$\begin{array}{l}\text { People per } \\
\text { room }\end{array}$} & \multicolumn{2}{|c|}{$\begin{array}{l}\text { Education of } \\
\text { mother }\end{array}$} & \multicolumn{2}{|c|}{$\begin{array}{l}\text { Education of } \\
\text { father }\end{array}$} \\
\hline & $F$ & $p$ & $F$ & $P$ & $F$ & $p$ & $F$ & $p$ & $F$ & $p$ & $F$ & $p$ & $F$ & $p$ \\
\hline At least 1 type of ACE & 0.33 & 0.57 & 0.12 & 0.73 & 0.26 & 0.77 & 0.42 & 0.66 & 0.03 & 0.97 & 1.71 & 0.18 & 0.55 & 0.58 \\
\hline Violence victim ${ }^{\#}$ & 1.08 & 0.30 & 0.01 & 0.94 & 2.46 & 0.09 & 0.60 & 0.55 & 0.24 & 0.79 & 0.68 & 0.51 & 3.71 & 0.03 \\
\hline Stressful family problems & 0.04 & 0.85 & 0.53 & 0.47 & 1.01 & 0.36 & 0.32 & 0.72 & 0.54 & 0.58 & 1.11 & 0.33 & 0.87 & 0.42 \\
\hline Long separation from parents & 0.04 & 0.85 & 0.002 & 0.97 & 1.85 & 0.16 & 3.52 & $\mathbf{0 . 0 3}$ & 0.54 & 0.58 & 9.24 & $<0.001$ & 1.70 & 0.19 \\
\hline Other unspecified ${ }^{\#}$ & 0.03 & 0.86 & 0.04 & 0.85 & 2.68 & 0.07 & 1.91 & 0.15 & 0.89 & 0.41 & 2.69 & 0.07 & 1.58 & 0.21 \\
\hline
\end{tabular}

ACEs adverse childhood

${ }^{\#} 0$ (no ACE reported) vs 1 (specific ACE type occurrence in the life history), bold the relation is statistically significant at the level of $<0.05$

Fig. 1 The effects of interaction between an education of father and the experience of being victim of violence on the $z$ scores BMI

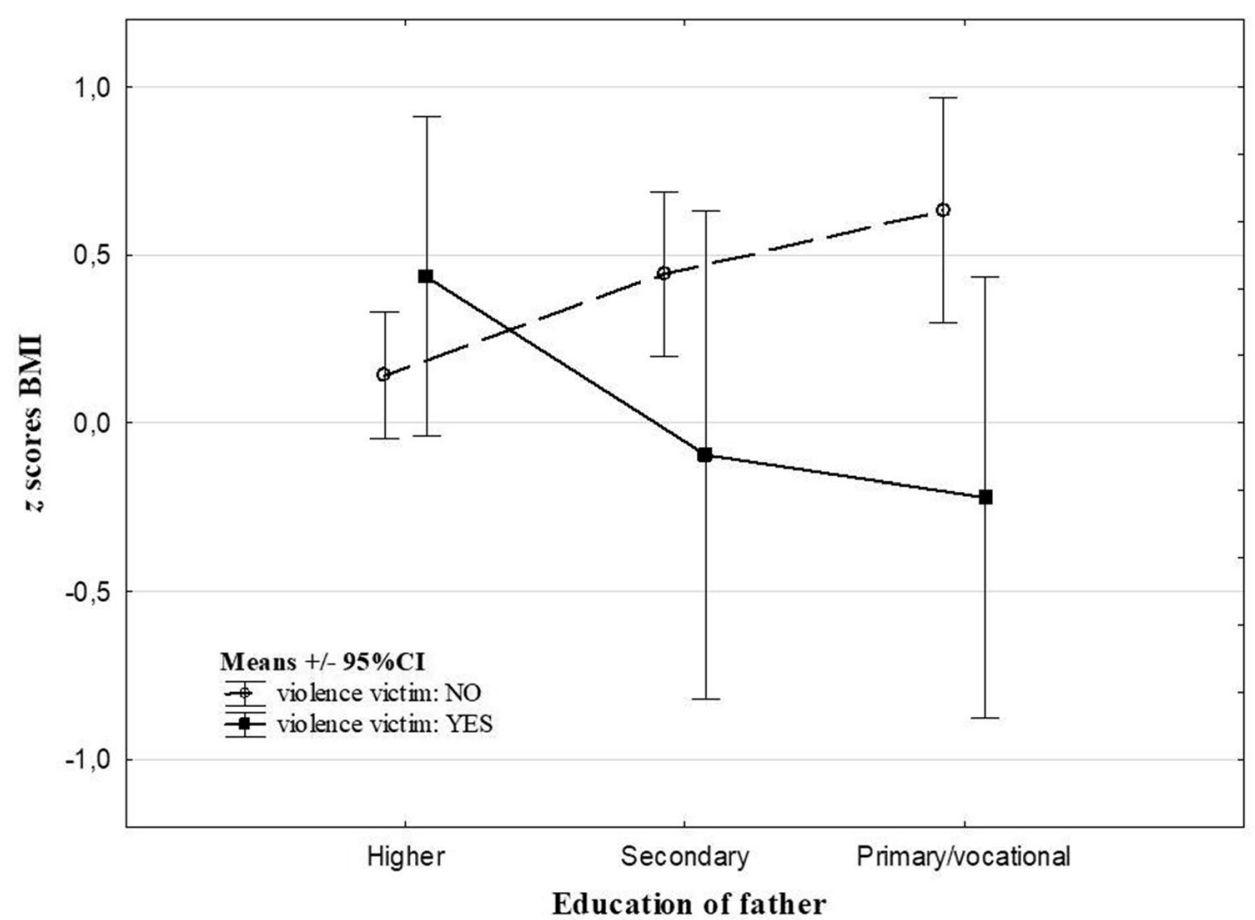

specifically children experienced trauma and whether these were one-time events or a permanent crisis. In future studies, it is worth expanding the questionnaire to include this perspective.

The analysis of the ACE score-underweight link gave the same outcomes as in the case of obesity. Although the $z$ scores BMI decreased with ACE accumulation, the trend was not statistically significant. Whereas, the study of Soares et al. [11] produced similar outcomes when the BMI and waist circumference were analysed in Brazilian adolescents, the ACE score was positively associated with obesity indices in the UK sample. The ACEs-underweight link has been revealed in several other studies [10, 12, 14]. The outcomes suggest the association of ACEs with abnormal weight is modulated by sex, socioeconomic status and ACE type. Thus, the effects of these factors on the ACEs $-z$ scores BMI relation were tested in our research. Significant results were found for the interaction between long separation from parents and parental subjective assessment of SES and maternal education, with the highest $z$ scores BMI in children of parents who declared the worst economic situation of family or whose mothers had finished education 
Fig. 2 The effects of interaction between parental subjective assessment of socioeconomic status of the family and the long separation from parents on the $z$ scores BMI

Fig. 3 The effects of interaction between an education of mother and the long separation from parents on the $z$ scores BMI
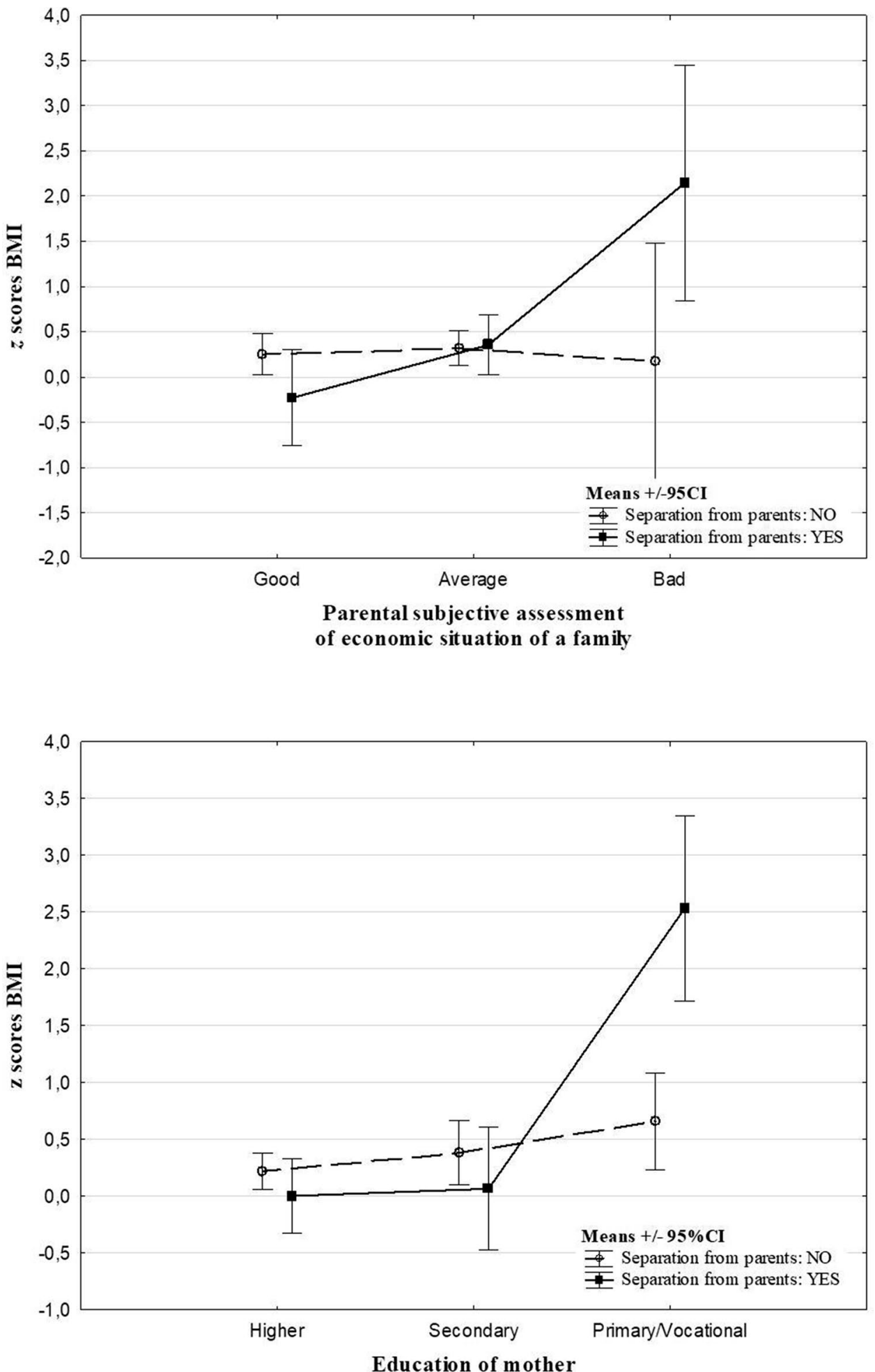

with a primary or vocational degree. This is in line with previous research. Despite of different method of economic situation assessment, similarities to our results were found in the work of Gardener et al. [26], which revealed an effect of interaction between income and adverse experiences on $z$ scores BMI in youth. Children from low-income households are likely to experience a disproportionate burden of psychosocial stressors, such as housing or food insecurity. These adverse experiences related to economic situation were previously found to be associated with obesity [28].

A gradual increase of $z$ scores BMI were found between higher and primary/vocational paternal education in children 
Fig. 4 The $z$ scores BMI by ACE score. The trend line and ANOVA results

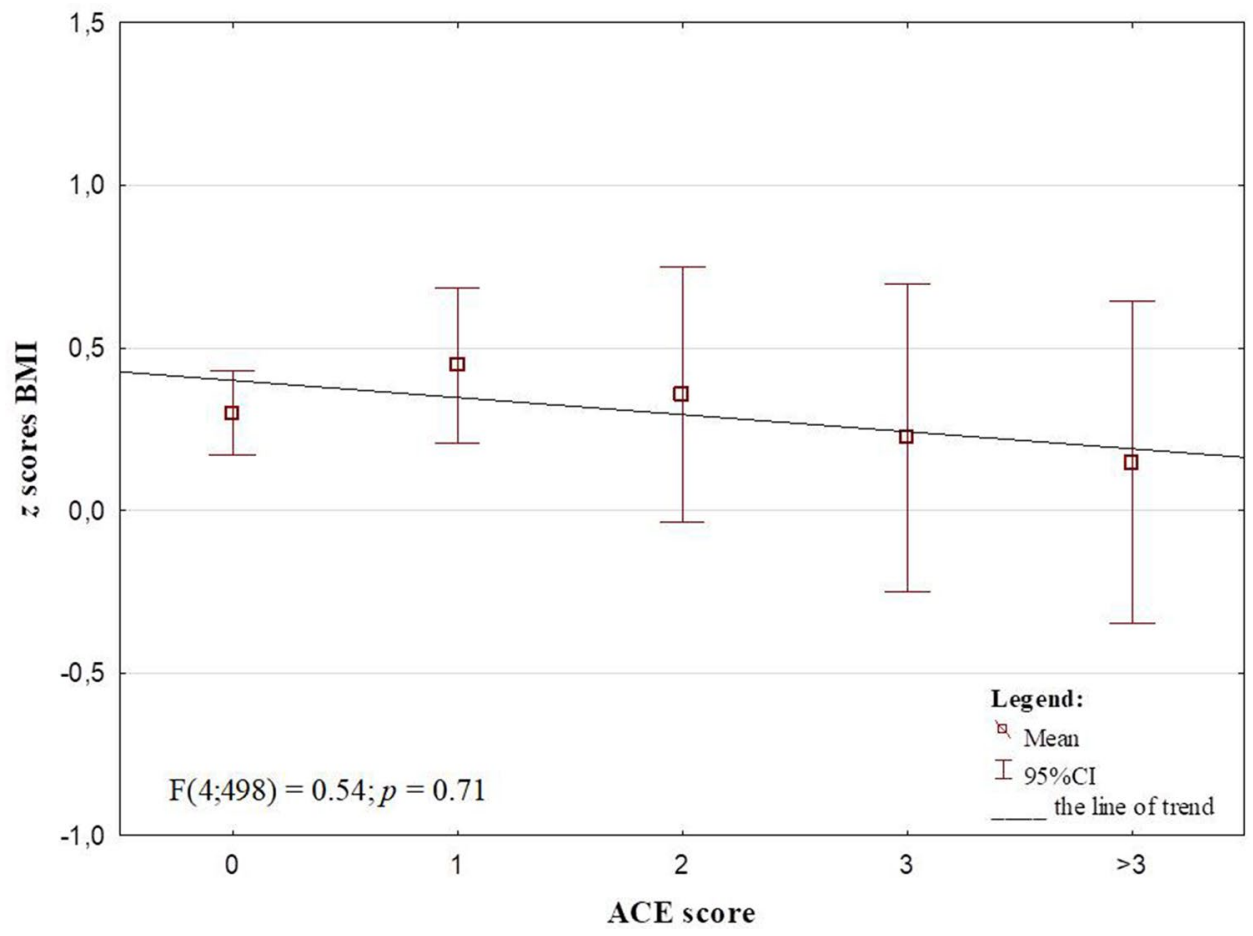

who were not violence victims. This corresponds with previous data showing the higher education of parents as a factor related to health awareness, and thus protection against obesity [29], and also underweight [30]. However, a combination of low paternal education and experience of violence was related to the lowest $z$ scores BMI. This may suggest some specific characteristics of violence as one of the ACE types and/ or partially different role of paternal and maternal education. Previous study on relationship between violence and weight status has revealed contrasting findings. Whitaker et al. [31] found psychological aggression and physical punishment unrelated to obesity in preschool children, whereas, neglect was associated with obesity independently of parental education in the same sample. The results of Sokol et al. [32] suggested maltreatment in adolescence, but not in childhood, was related to excess BMI. In contrast to these studies, our results showed a significant association of experiencing violence with both underweight and obesity. However, the $z$ scores BMI analysis indicated that paternal education may have a decisive influence on the type of weight abnormalities in the sample of children who experienced violence. Although both maternal and paternal education effects modulate the ACEs-weight relation, they may be related with different agents. Mothers often have a decisive effect on dietary and generally health-related habits of a family [33]. Thus, low maternal education, concomitant with a lower level of health awareness, may result in less healthy eating habits of a family and in consequence, obesity [34]. Because of the existing gender wage gap in Poland [35], fathers usually make a greater contribution to the household budget. Therefore, low parental education may affect the socio-economic status of a family to a greater extent than education of the mother. Low education of the father and low SES of a family was found previously to be related to an increased risk of different kinds of maltreatment, including violence $[36,37]$. What is more, low SES and violence seem to be aggregated with food insecurity [38], which is an important risk factor not only of obesity, but also underweight [39]. This is in line with our previous study on the effects of parental alcohol addiction, which is important risk factor of child abuse and neglect [40]. The research revealed that children from fragile families characterised by parental alcohol addiction and low economic status were at high risk of underweight, and not of obesity [14]. These results suggest that under high stress conditions, and in families with very low socio-economic status, the strategy of reducing discomfort through food may be unavailable. Therefore, underweight may be the one of expected outcome in such situations.

The association of ACEs and body weight abnormalities could be explained by the development of a thrifty phenotype under the influence of adverse life events [41].The thrifty phenotype leads to changes in the child's metabolism [42], which are related with reduced energy expenditure [43], but also with greater susceptibility to the consumption of large amounts of food [44]. Overeating can be fostered by hormonal changes under the influence of stressors [45], among others. Cortisol, which promotes the deposition of fatty tissue in the abdominal area [46], which increases the risk of cardiovascular disease [47]. In addition, the increased 
concentration of cortisol inhibits lipolysis [48], which further reduces fat burning and promotes overweight. As shown previously, epigenetic changes have been found in several genes participating in regulation of glucose and fat metabolism [49]. The dysregulation of hypothalamic-pituitary-adrenal (HPA) and altered cortisol stress response in people who experienced ACEs may be a mediator between ACEs and failing health [50]. Thus, underweight and obesity may be the effects of different, genetically determined metabolic predispositions triggered by ACEs. Neurobiological regulation of emotions may also play an important role. Obesity was linked previously to low self-regulation, low inhibitory control skills and dysregulation in the reward pathways [28]. Early traumatic experiences can deregulate a child's developing neurobiological system, making them less resilient to stressful events [51]. ACEs can have an impairing effect on prefrontal cortex, associated with emotion self-regulation [52]. As a result, the child may engage in maladaptive coping strategies such as emotional eating $[53,54]$. People who have experienced strong stressors are more prone to eating disorders $[55,56]$ leading to both food restriction and overeating [57]. ACEs may also be related to the increased occurrence of addictions [58], which are also associated with changes in body weight [59]. Future research on the ACEs-body mass relation should consider a closer examination of these mechanisms.

\section{Conclusions}

The study revealed an association of adverse childhood experiences with obesity and underweight in children. The effect of ACEs on weight abnormalities was significant and distinct from sex and family characteristics. Nevertheless, the results indicate the interactions between the types of ACE, economic situation of a family and education of parents as possible modulators of ACEs-BMI association. The study implicates the need for both obesity and underweight prevention in individuals with adverse experiences as early as in childhood.

\section{Strength and limits}

Unlike most other studies, this research tested the relation of ACEs to both obesity and underweight in children. The associations were checked for several factors in statistical analysis. What is more, the role of ACE type, sex and socioeconomic status indices as modulators of the link between ACEs and BMI was included in the analysis.

Despite the strengths of the research, there are also limitations that should be taken into consideration. The study is of a cross-sectional nature with a parental retrospective assessment of adverse childhood experiences and we did not collect any data on the height and weight of the children prior to the study. Thus, we can only conclude on the association, not causal relationship of ACEs and weight status. We cannot exclude that revealed link between ACEs and body size is partially related to greater risk of specific types of adverse experiences, e.g. peer violence, among underweight and obese children. Nevertheless, it is highly unlikely for most types of the ACE tested to be a consequence of child's characteristics.

Parental retrospective assessment of ACEs in children may lead to underestimation, nevertheless, we decided not to question the children on ACEs directly, as potentially harmful. We also did not assess the timing and duration of exposure to ACEs. These characteristics of stress may partially explain the diversified results on ACEs-weight relation. The study was conducted on a relatively large sample, nevertheless, the low number of cases in some groups, may have resulted in insufficient statistical power and increased risk of type II error. The study was aimed to explore the interactions between ACEs, possible modulators and body size. We did not control the results of our analyses for multiple testing, therefore, type I errors cannot be excluded, either. The results obtained need to be replicated in future research.

\section{What is already known on this subject?}

An association between adverse childhood experiences (ACEs) and obesity was found in adults, but the studies of children and adolescents gave contrasting findings. ACEs may be related not only to obesity but also to underweight. Nevertheless, studies including possible ACEs-underweight association are sparse and have produced inconsistent results.

\section{What this study adds?}

The research presents important results on the ACEs-obesity as well as ACEs-underweight link. The associations were found to be significant in school age children. The role of such modulators as the ACE types, economic situation of a family and the level of education of parents has been revealed.

Author contributions TH, AS and MD-W: conceptualization; TH, MD-W, AS, ARB, EP: methodology; TH, EB and PS: formal analysis; TH, EB, PS, AD, AS, MD-W and EP: investigation; MD-W, EB and PS: data curation; TH: original draft preparation, TH, EB, PS, AD, ARB, EP, AS and MD-W: review and editing of the draft; TH, AS and MD-W: supervision; MD-W, TH and AS: project administration; 
MD-W, TH and AS: funding acquisition. All authors have read and agreed to the published version of the manuscript.

Funding The study was funded by the National Science Centre, Poland, grant number: 2016/21/B/NZ5/00492.

Data availability Because of the sensitive nature of the data supporting the conclusions of this article, only selective access to data is offered on reasonable request to the principal investigator (MD-W).

\section{Declarations}

Conflict of interest TH, EB and PS have received travel support and speaker fee from MEDICE Arzneimittel Pütter GmbH and Co. KG in 2019. AD, AB, EP, AS and MD-W declare no conflict of interest.

Ethical approval The work described has been carried out in accordance with The Code of Ethics of the World Medical Association (Declaration of Helsinki) for experiments involving humans and approved by the Institutional Bioethics Board of Poznan University of Medical Sciences (approval no. 542/14).

Consent to participate The subjects and their legal guardians were fully informed about the research procedures and legal guardians gave a written consent to participate in the study.

Consent for publication Not applicable.

Open Access This article is licensed under a Creative Commons Attribution 4.0 International License, which permits use, sharing, adaptation, distribution and reproduction in any medium or format, as long as you give appropriate credit to the original author(s) and the source, provide a link to the Creative Commons licence, and indicate if changes were made. The images or other third party material in this article are included in the article's Creative Commons licence, unless indicated otherwise in a credit line to the material. If material is not included in the article's Creative Commons licence and your intended use is not permitted by statutory regulation or exceeds the permitted use, you will need to obtain permission directly from the copyright holder. To view a copy of this licence, visit http://creativecommons.org/licenses/by/4.0/.

\section{References}

1. Elsenburg LK, van Wijk KJE, Liefbroer AC, Smidt N (2017) Accumulation of adverse childhood events and overweight in children: a systematic review and meta-analysis. Obesity 25:820-832. https://doi.org/10.1002/oby.21797

2. Fuemmeler BF, Dedert E, McClernon FJ, Beckham JC (2009) Adverse childhood events are associated with obesity and disordered eating: results from a U.S. Population-based survey of young adults. J Trauma Stress 22:329-333. https://doi.org/10. $1002 /$ jts. 20421

3. Vámosi M, Heitmann BL, Kyvik KO (2010) The relation between an adverse psychological and social environment in childhood and the development of adult obesity: a systematic literature review. Obes Rev 11:177-184. https://doi.org/10.1111/j.1467-789X.2009. 00645.x

4. Llabre MM, Schneiderman N, Gallo LC et al (2017) Childhood trauma and adult risk factors and disease in hispanics/latinos in the US: results from the Hispanic Community Health Study/Study of Latinos (HCHS/SOL) Sociocultural Ancillary Study. Psychosom
Med 79:172-180. https://doi.org/10.1097/PSY.0000000000 000394

5. Gebreab SZ, Vandeleur CL, Rudaz D et al (2018) Psychosocial stress over the lifespan, psychological factors, and cardiometabolic risk in the community. Psychosom Med 80:628-639. https:// doi.org/10.1097/PSY.0000000000000621

6. Davis L, Barnes AJ, Gross AC et al (2019) Adverse childhood experiences and weight status among adolescents. J Pediatr 204:71-76.e1. https://doi.org/10.1016/j.jpeds.2018.08.071

7. Danese A, Tan M (2014) Childhood maltreatment and obesity: systematic review and meta-analysis. Mol Psychiatry 19:544-554. https://doi.org/10.1038/mp.2013.54

8. Schroeder K, Schuler BR, Kobulsky JM, Sarwer DB (2021) The association between adverse childhood experiences and childhood obesity: a systematic review. Obes Rev 22:e13204. https://doi.org/ 10.1111/obr.13204

9. Gilbert R, Widom CS, Browne K et al (2009) Burden and consequences of child maltreatment in high-income countries. Lancet 373:68-81. https://doi.org/10.1016/S0140-6736(08)61706-7

10. Lown EA, Lui CK, Karriker-Jaffe K et al (2019) Adverse childhood events and risk of diabetes onset in the 1979 National longitudinal survey of youth cohort. BMC Public Health 19:1007. https://doi.org/10.1186/s12889-019-7337-5

11. Soares ALG, Matijasevich A, Menezes AMB et al (2018) Adverse childhood experiences (ACEs) and adiposity in adolescents: a cross-cohort comparison. Obesity 26:150-159. https://doi.org/ 10.1002/oby. 22035

12. Roenholt S, Beck NN, Karsberg SH, Elklit A (2012) Posttraumatic stress symptoms and childhood abuse categories in a national representative sample for a specific age group: associations to body mass index. Eur J Psychotraumatol. https://doi. org/10.3402/ejpt.v3i0.17188.10.3402/ejpt.v3i0.17188

13. Isohookana R, Marttunen M, Hakko H et al (2016) The impact of adverse childhood experiences on obesity and unhealthy weight control behaviors among adolescents. Compr Psychiatry 71:17-24. https://doi.org/10.1016/j.comppsych.2016.08.002

14. Hanć T, Czapla Z, Szwed A et al (2015) Growth and nutritional status of children from dysfunctional families with alcohol addicted parents in Poland. Econ Hum Biol 18:101-109. https://doi.org/10.1016/j.ehb.2015.05.003

15. Ghosh-Ippen C, Ford J, Racusin R et al (2002) Trauma events screening inventory-parent report revised. San Francisco

16. Felitti VJ, Anda RF, Nordenberg D et al (1998) Relationship of childhood abuse and household dysfunction to many of the leading causes of death in adults: The Adverse Childhood Experiences (ACE) Study. Am J Prev Med 14:245-258. https://doi. org/10.1016/S0749-3797(98)00017-8

17. de Onis M, Onyango AW, Borghi E et al (2007) Development of a WHO growth reference for school-aged children and adolescents. Bull World Health Organ 85:660-667. https://doi.org/ 10.2471/blt.07.043497

18. Cole T, Bellizzi M, Flegal K, Dietz W (2000) Establishing standard definition for child overweight and obesity worldwide: International survey. BMJ (Clin Res ed) 320:1240-1243

19. Cole T, Flegal K, Nicholls D, Jackson A (2007) Body mass index cut offs to define thinness in children and adolescents: International survey. BMJ (Clin Res ed) 335:194. https://doi. org/10.1136/bmj.39238.399444.55

20. Mozylowski P, Kalinowska K (2014) The Gray Zone in Poland-phenomenon, conditions and causes, multifaceted consequences. IJEBA 2:15-26

21. Cwiąkała-Małys A, Piotrowska I (2017) The problem of the grey area in e-Trade in Poland. Barometr Regionalny 15:41-49

22. Cable N, Sacker A (2019) Validating overcrowding measures using the UK Household Longitudinal Study. SSM - Population Health 8:100439. https://doi.org/10.1016/j.ssmph.2019.100439 
23. Charmandari E, Kino T, Souvatzoglou E, Chrousos GP (2003) Pediatric stress: hormonal mediators and human development. Horm Res 59:161-179. https://doi.org/10.1159/000069325

24. Scaglioni S, De Cosmi V, Ciappolino V et al (2018) Factors influencing children's eating behaviours. Nutrients 10:706. https://doi.org/10.3390/nu10060706

25. McKelvey LM, Edge NC, Mesman GR et al (2018) Adverse experiences in infancy and toddlerhood: relations to adaptive behavior and academic status in middle childhood. Child Abuse Negl 82:168-177. https://doi.org/10.1016/j.chiabu.2018.05.026

26. Gardner R, Feely A, Layte R et al (2019) Adverse childhood experiences are associated with an increased risk of obesity in early adolescence: a population-based prospective cohort study. Pediatr Res 86:522-528. https://doi.org/10.1038/ s41390-019-0414-8

27. Herzog JI, Schmahl C (2018) Adverse childhood experiences and the consequences on neurobiological, psychosocial, and somatic conditions across the lifespan. Front Psych 9:420. https://doi.org/ 10.3389/fpsyt.2018.00420

28. Suglia SF, Duarte CS, Chambers EC, Boynton-Jarrett R (2012) Cumulative social risk and obesity in early childhood. Pediatrics 129:e1173-1179. https://doi.org/10.1542/peds.2011-2456

29. Antonogeorgos G, Panagiotakos DB, Grigoropoulou D et al (2013) The mediating effect of parents' educational status on the association between adherence to the Mediterranean diet and childhood obesity: the PANACEA study. Int J Public Health 58:401-408. https://doi.org/10.1007/s00038-012-0424-3

30. Vollmer S, Bommer C, Krishna A et al (2017) The association of parental education with childhood undernutrition in low- and middle-income countries: comparing the role of paternal and maternal education. Int J Epidemiol 46:312-323. https://doi.org/ 10.1093/ije/dyw 133

31. Whitaker RC, Phillips SM, Orzol SM, Burdette HL (2007) The association between maltreatment and obesity among preschool children. Child Abuse Negl 31:1187-1199. https://doi.org/10. 1016/j.chiabu.2007.04.008

32. Sokol RL, Ennett ST, Shanahan ME et al (2019) Maltreatment experience in childhood and average excess body mass from adolescence to young adulthood. Child Abuse Negl 96:104070. https://doi.org/10.1016/j.chiabu.2019.104070

33. Goodwin P, Garrett D, Galal O (2005) Women and Family Health: The Role of Mothers in Promoting Family and Child Health. International Journal of Global Health and Health Disparities 4:30-42

34. Williams L, Campbell K, Abbott $\mathrm{G}$ et al (2012) Is maternal nutrition knowledge more strongly associated with the diets of mothers or their school-aged children? Public Health Nutr 15:1396-1401. https://doi.org/10.1017/S1368980011003430

35. Goraus K, Tyrowicz J (2014) Gender wage gap in Poland - can it be explained by differences in observable characteristics? Working Pap 11:1-19

36. Fourth National Incidence Study of Child Abuse and Neglect (NIS-4): Report to Congress. https://www.acf.hhs.gov/opre/ report/fourth-national-incidence-study-child-abuse-and-neglectnis-4-report-congress. Accessed 10 Sep 2021

37. Stalmach M, Tabak I, Radiukiewicz K (2014) Selected family socio-economic factors as predictors of peer violence among school children in Poland. Dev Period Med 18:495-505

38. Helton JJ, Jackson DB, Boutwell BB, Vaughn MG (2019) Household food insecurity and parent-to-child aggression. Child Maltreat 24:213-221. https://doi.org/10.1177/1077559518819141

39. Moradi S, Mirzababaei A, Mohammadi H et al (2019) Food insecurity and the risk of undernutrition complications among children and adolescents: a systematic review and meta-analysis. Nutrition 62:52-60. https://doi.org/10.1016/j.nut.2018.11.029

40. Laslett A-M, Room R, Dietze P, Ferris J (2012) Alcohol's involvement in recurrent child abuse and neglect cases. Addiction
107:1786-1793. https://doi.org/10.1111/j.1360-0443.2012. 03917.x

41. Money J (1982) Child abuse: growth failure, IQ deficit, and learning disability. J Learn Disabil 15:579-582. https://doi.org/10. $1177 / 002221948201501002$

42. Dulloo AG (2006) Regulation of fat storage via suppressed thermogenesis: a thrifty phenotype that predisposes individuals with catch-up growth to insulin resistance and obesity. Horm Res 65(Suppl 3):90-97. https://doi.org/10.1159/000091512

43. Reinhardt M, Thearle MS, Ibrahim M et al (2015) A human thrifty phenotype associated with less weight loss during caloric restriction. Diabetes 64:2859-2867. https://doi.org/10.2337/db14-1881

44. Piaggi P, Vinales KL, Basolo A et al (2018) Energy expenditure in the etiology of human obesity: spendthrift and thrifty metabolic phenotypes and energy-sensing mechanisms. J Endocrinol Invest 41:83-89. https://doi.org/10.1007/s40618-017-0732-9

45. Torres SJ, Nowson CA (2007) Relationship between stress, eating behavior, and obesity. Nutrition 23:887-894. https://doi.org/10. 1016/j.nut.2007.08.008

46. Paredes S (1992) Ribeiro L (2014) Cortisol: the villain in metabolic syndrome? Rev Assoc Med Bras 60:84-92. https://doi.org/ 10.1590/1806-9282.60.01.017

47. Gruzdeva O, Borodkina D, Uchasova E et al (2018) Localization of fat depots and cardiovascular risk. Lipids Health Dis 17:218. https://doi.org/10.1186/s12944-018-0856-8

48. Ottosson M, Lönnroth P, Björntorp P, Edén S (2000) Effects of cortisol and growth hormone on lipolysis in human adipose tissue1. J Clin Endocrinol Metab 85:799-803. https://doi.org/10. 1210/jcem.85.2.6358

49. Kaufman J, Montalvo-Ortiz JL, Holbrook H et al (2018) Adverse childhood experiences, epigenetic measures, and obesity in youth. J Pediatr 202:150-156.e3. https://doi.org/10.1016/j.jpeds.2018.06. 051

50. Tang R, Howe LD, Suderman M et al (2020) Adverse childhood experiences, DNA methylation age acceleration, and cortisol in UK children: a prospective population-based cohort study. Clin Epigenetics 12:55. https://doi.org/10.1186/s13148-020-00844-2

51. Giotakos O (2020) Neurobiology of emotional trauma. Psychiatriki 31:162-171

52. Kalia V, Knauft K (2020) Emotion regulation strategies modulate the effect of adverse childhood experiences on perceived chronic stress with implications for cognitive flexibility. PLoS ONE 15:e0235412. https://doi.org/10.1371/journal.pone.0235412

53. Burns EE, Fischer S, Jackson JL, Harding HG (2012) Deficits in emotion regulation mediate the relationship between childhood abuse and later eating disorder symptoms. Child Abuse Negl 36:32-39. https://doi.org/10.1016/j.chiabu.2011.08.005

54. Kong S, Bernstein K (2009) Childhood trauma as a predictor of eating psychopathology and its mediating variables in patients with eating disorders. J Clin Nurs 18:1897-1907. https://doi.org/ 10.1111/j.1365-2702.2008.02740.x

55. Trottier K, MacDonald DE (2017) Update on psychological trauma, other severe adverse experiences and eating disorders: state of the research and future research directions. Curr Psychiatry Rep 19:45. https://doi.org/10.1007/s11920-017-0806-6

56. Molendijk ML, Hoek HW, Brewerton TD, Elzinga BM (2017) Childhood maltreatment and eating disorder pathology: a systematic review and dose-response meta-analysis. Psychol Med. https://doi.org/10.1017/S0033291716003561

57. Palmisano GL, Innamorati M, Vanderlinden J (2016) Life adverse experiences in relation with obesity and binge eating disorder: a systematic review. J Behav Addict 5:11-31. https://doi.org/10. 1556/2006.5.2016.018

58. Lim MSM, Cheung FYL, Kho JM, Tang CS-K (2020) Childhood adversity and behavioural addictions: the mediating role of emotion dysregulation and depression in an adult community sample. 
Addict Res Theory 28:116-123. https://doi.org/10.1080/16066 359.2019.1594203

59. Bourdier L, Orri M, Carre A et al (2018) Are emotionally driven and addictive-like eating behaviors the missing links between psychological distress and greater body weight? Appetite 120:536546. https://doi.org/10.1016/j.appet.2017.10.013
Publisher's Note Springer Nature remains neutral with regard to jurisdictional claims in published maps and institutional affiliations. 